Article

\title{
Potential Synergism between Novel Metal Complexes and Polymeric Brominated Flame Retardants in Polyamide 6.6
}

\author{
Alistair F. Holdsworth ${ }^{1,2}\left(\mathbb{D}\right.$, A. Richard Horrocks ${ }^{1, *(\mathbb{D}}$ and Baljinder K. Kandola ${ }^{1}(\mathbb{D}$ \\ 1 Institute for Materials Research and Innovation, University of Bolton, Deane Road, Bolton, Greater \\ Manchester BL3 6HQ, UK; alistair.holdsworth@manchester.ac.uk (A.F.H.); B.Kandola@bolton.ac.uk (B.K.K.) \\ 2 Now at School of Chemical Engineering and Analytical Sciences, University of Manchester, Oxford Road, \\ Manchester M13 9PL, UK \\ * Correspondence: a.r.horrocks@bolton.ac.uk
}

Received: 3 June 2020; Accepted: 8 July 2020; Published: 13 July 2020

\begin{abstract}
While environmental concerns have caused polymeric brominated primary flame retardants (PolyBrFRs) to be effective replacement monomeric species, few alternatives for antimony trioxide (ATO) have been developed beyond the zinc stannates ( $\mathrm{ZnSs})$. Previous research, which explored the interactions of aluminium (AlW), tin (II) (SnW) and zinc ( $\mathrm{ZnW}$ ) tungstates with several phosphorus-containing flame retardants in polyamide 6.6 (PA66), is extended to two PolyBrFRs: brominated polystyrene (BrPS), and poly(pentabromobenzyl acrylate) (BrPBz). On assessing the effect of each tungstate on the thermal degradation and flammability in combination with each PolyBrFR using TGA, UL94, LOI, cone calorimetry and TGA-FTIR, only ZnW and SnW showed significant increases in LOI (>26 vol.\%). Both ZnW-BrPS- and ZnW-BrPBz-containing formulations yielded average UL94 ratings $\geq \mathrm{V}-2$ and TGA char residues (corrected for metals content at $500{ }^{\circ} \mathrm{C}$ ) in air $>15 \mathrm{wt} . \%$. BrPS-containing samples, especially those containing $\mathrm{ZnW}$ and $\mathrm{SnW}$, generated peak heat release rates approximately $50 \%$ lower than the equivalent $\mathrm{BrPBz}$ samples. These reductions did not correlate with respective increases in LOI, suggesting that tungstate-PolyBrFR combinations influence pre-ignition differently to post-ignition behaviour. Calculated synergistic effectivities indicate that $\mathrm{ZnW}$ functions as a synergist in both pre- and post-ignition stages, especially with BrPS. TGA-FTIR and char analyses showed that, in addition to the vapour-phase activity normally associated with PolyBrFRs, condensed-phase processes occurred, especially for the ZnW-PolyBrFR combinations. Additionally, $\mathrm{ZnW}$ demonstrated significant smoke-suppressing properties comparable with zinc stannate $(\mathrm{ZnS})$.
\end{abstract}

Keywords: polyamide 6.6; tungstates; zinc stannate; synergism; bromine; flammability; thermal analysis; flame retardant; polymers; smoke; mechanistic determination

\section{Introduction}

The environmental pressures on halogen-containing and particularly bromine-containing flame retardants (BrFRs) began during the late 1980s, when concerns were raised about the formation of dioxins when polymers containing them were incinerated [1]. During the next 30 years the focus of concerns changed to their potential toxicological effects, particularly of polybrominated diphenyls and diphenyl ethers during the 1990s, leading to bans on the production and use of the former and similar restrictions of selected examples of the latter such as penta- and octa-bromo diphenylene ethers in 2005 [2,3]. Subsequently, and in spite of its widespread use and successful survival of risk assessments [4], decabromodiphenyl ether, because of evidence of its bioaccumulation and toxicity 
of its degradation products in the environment, has been similarly banned within both the USA [5] and EU [6]. However, in its place, polybrominated flame retardants such as brominated polystyrene and poly(pentabromobenzyl acrylate) are often used since their polymeric nature binds them into a polymeric or coating formulation, thereby reducing their ability to leach out into the surroundings [7] and so pollute the environment [8].

As the synergist antimony (III) oxide or trioxide (ATO or $\mathrm{Sb}_{2} \mathrm{O}_{3}$ ) is used in combination with the majority of halogen-based flame retardants, FRs, in use, attention has also recently focused upon its toxicity and potential carcinogenicity [9], although since about 1989 alternatives such as the low-toxicity zinc stannates ( $\mathrm{ZnSs}$ ) have been available, but at a higher price [10-12]. The zinc stannates also have the advantage of suppressing smoke, a further disadvantage of ATO, which tends to increase smoke formation. However, the $\mathrm{ZnSs}$ are not equally effective with all BrFRs and so may only be used with selected examples [12,13], though evidence of interactions with non-halogen-containing flame retardants such as those containing phosphorus are known [14].

Recent research by ourselves investigated over 150 metal complexes for their ability to promote char in polyamide 6.6 (PA66), chosen as a typical engineering polyamide of which zinc oxalate [15] was shown to interact positively with poly(pentabromobenzyl acrylate) in terms of reduction in cone calorimetric peak heat release rate (PHRR) and increased residual char levels. Subsequent work showed that aluminium (AlW), tin (II) (SnW) and zinc ( $\mathrm{ZnW}$ ) tungstates not only increased char formation and reduced PHRR values when present alone in PA66 [16], but when also in the presence of the phosphorus-containing FRs, aluminium diethyl phosphinate (AlPi) and AlPi in the presence of melamine polyphosphate, they increased their respective FR behaviours and, in the case of $\mathrm{ZnW}$, reduced smoke formation [17].

The aim of this paper is to assess the interactions of these tungstates with the PolyBrFRs brominated polystyrene (BrPS) and poly(pentabromobenzyl acrylate) (BrPBz) when compounded in PA66 with respect to flammability performance, determination of potential mechanisms of action, and study of any potential synergism.

\section{Experimental}

\subsection{Materials}

The three tungstates ( $\mathrm{AlW}, \mathrm{SnW}$ and $\mathrm{ZnW}$ ) were synthesised and characterised as previously reported [16]. These materials were calcined at $240{ }^{\circ} \mathrm{C}$ (under vacuum for $\mathrm{SnW}$, to suppress oxidation of Sn (II) to Sn (IV)). Pure PA66 was acquired from Invista Engineering Polymers (compounding grade, $100 \%$ PA66, m.pt. $260^{\circ} \mathrm{C}$, MFI $19.56 \mathrm{~g} / \mathrm{min} @ 280^{\circ} \mathrm{C}$ ), UK; brominated polystyrene (BrPS) and poly(pentabromobenzyl acrylate) (BrPBz), as commercial products FR803 (66 wt.\% Br) and FR1025 (71 wt.\% Br), respectively, were supplied by ICL-IP Ltd. These have the respective generic formulae as illustrated in Figure 1.
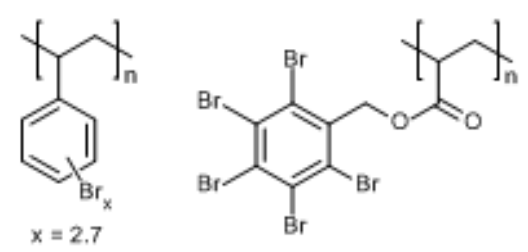

Figure 1. Structures of brominated polystyrene, BrPS (left) and poly(pentabromobenzyl acrylate), $\mathrm{BrPBz}$ (right).

\subsection{Polymer Composite Compounding}

Compounding of all PA66 formulations has been described elsewhere, $[16,17]$ but is repeated briefly here for convenience. This was undertaken using a laboratory-scale Thermo-Scientific twin-screw extruder with six barrel heating elements set progressively at $250,255,260,265,270$ and $275{ }^{\circ} \mathrm{C}$ at a 
screw speed of $350 \mathrm{rpm}$. Prior to compounding, all PA66 polymer pellets and previously calcined flame retardant additive powders were dried at $80^{\circ} \mathrm{C}$ for at least $36 \mathrm{~h}$ before processing.

Formulations outlined in Table 1 were selected based on the previous observations that $5 \mathrm{wt} . \%$ of each tungstate alone provided a marginal improvement in flame retardancy [16] and represented a typical level of inorganic synergist used commercially [18]. Additionally, compounding higher levels, especially AlW, proved to be difficult. Each PolyBrFR was present at $10 \mathrm{wt} . \%$, a level that alone provided only a marginal increase in flame retardancy, but when in the presence of a typical synergist like ATO or ZnS would provide a possibly acceptable higher level [13].

Table 1. Thermogravimetric and differential thermogravimetric (TGA/DTG) results for PA66/tungstate/PolyBrFR formulations in air.

\begin{tabular}{ccccccccc}
\hline Sample & PA66 & $\mathbf{B r}(\mathbf{B r P S})$ & $\mathbf{B r}(\mathbf{B r P B z})$ & $\mathbf{M C}^{*}$ & \multicolumn{3}{c}{ TGA/DTG (Air) } \\
\hline & \multicolumn{3}{c}{ Concentration, wt. $\%$} & & $\mathbf{T}_{\mathbf{5} \%}$ & $\mathbf{T}_{\mathbf{m a x}}{ }^{\circ} \mathbf{C}$ & $\mathbf{R}_{\mathbf{5 0 0}, \mathbf{w t} . \mathbf{\%}}{ }^{*}$ & $\mathbf{R}_{\mathbf{5 8 0}, \mathbf{w t} . \%}$ \\
\hline PA66 & 100.0 & & & 386 & 461 & 11.2 & 3.9 \\
BrPS & 90.0 & 10.0 & & & 400 & 430 & 8.1 & 0.5 \\
BrPBz & 90.0 & & 10.0 & & 363 & 402 & 10.6 & 1.2 \\
AlW-BrPS & 85.0 & 10.0 & & 5.0 & 374 & 423 & $15.9(10.9)$ & 4.4 \\
ZnW-BrPS & 85.0 & 10.0 & & 5.0 & 375 & 431 & $20.4(15.4)$ & 9.6 \\
SnW-BrPS & 85.0 & 10.0 & & 5.0 & 368 & 424 & $20.9(15.9)$ & 10.3 \\
AlW-BrPBz & 85.0 & & 10.0 & 5.0 & 367 & 405 & $15.1(10.1)$ & 4.6 \\
ZnW-BrPBz & 85.0 & & 10.0 & 5.0 & 358 & 404 & $26.2(21.2)$ & 20.8 \\
SnW-BrPBz & 85.0 & & 10.0 & 5.0 & 357 & 410 & $20.5(15.5)$ & 9.2 \\
\hline
\end{tabular}

Key: $\mathrm{BrPS}$ = brominated polystyrene; $\mathrm{BrPBz}=$ poly(pentabromobenzyl acrylate); $\mathrm{MC}^{*}$ indicates each tungstate; $\mathrm{T}_{5 \%}$ is the temperature to $5 \%$ mass loss, $\mathrm{T}_{\max }$ is the DTG peak rate of mass loss, and $\mathrm{R}_{500}$ and $\mathrm{R}_{580}$ are the residues levels at those temperatures respectively $\left(\right.$ in $\left.{ }^{\circ} \mathrm{C}\right) ;{ }^{*}$ bracketed values $=\left(\mathrm{R}_{500}-5\right) \%$.

Dry compounded pellets were pressed into plaques $(170 \times 170 \times 3 \mathrm{~mm})$ using a hot press at $260^{\circ} \mathrm{C}$ with a pressure of $20 \mathrm{~kg} / \mathrm{cm}^{2}$, followed by cutting into strips $12.7 \mathrm{~mm}$ wide for UL94 and LOI testing and $75 \times 75 \mathrm{~mm}$ plaques for cone calorimetric analysis, where appropriate.

\subsection{Fire Testing}

Compounded PA66 samples were assessed for Limiting Oxygen Index (LOI) according to ASTM 2863, subjected to the UL-94 test in the vertical orientation, according to ISO 1210 and analysed by cone calorimetry at $50 \mathrm{~kW} / \mathrm{m}^{2}$ heat flux (FTT cone calorimeter, Fire Testing Technology, UK) according to ISO 5660. Principal parameters determined included the peak heat release rate (PHHR), total heat release rate (THR) and total smoke release (TSR), with associated average errors of $<10 \%$ [19].

\subsection{Thermogravimetric and TGA-FTIR Analysis}

Simultaneous thermogravimetric and differential thermal analyses (TGA/DTA) were conducted using a TA Instruments SDT 2960 analyser, with nominal sample masses of 10-12 mg and under a $100 \mathrm{~mL} / \mathrm{min}$ flow of either air or nitrogen, using the method described elsewhere [15,17]. At least two experiments were undertaken for each sample. Transition temperatures were considered to be within $\pm 1^{\circ} \mathrm{C}$. For TGA-FTIR studies, as also described in greater detail elsewhere [17,19], samples were heated from ambient to $600{ }^{\circ} \mathrm{C}$ at either 10 or $20^{\circ} \mathrm{C} / \mathrm{min}$, the latter being used for the TGA-FTIR evolved gas analysis experiments. In the latter, the exhaust from the SDT 2960 thermal analytical module was connected to a heated gas cell (Thermo-Fisher Nicolet iS10) maintained at $250{ }^{\circ} \mathrm{C}$ mounted on a Thermo-Fisher Nicolet iS7 FTIR spectrometer via a heated, stainless steel gas line at $250^{\circ} \mathrm{C}$. Before each analysis, a $5 \mathrm{~min}$ isothermal equilibration stage at $100{ }^{\circ} \mathrm{C}$ was undertaken. FTIR data acquisition was started when the TGA/DTA ramp began with a gas transit time of $45 \mathrm{~s}$ from the exhaust of the TGA to the FTIR cell. 
As described previously [17], the key evolved species, carbon dioxide, ammonia and aliphatic species including cyclopentanone that are possible fuels (designated $\mathrm{CH}_{\mathrm{x}}$ ), were identified as being key indicators of significant mechanistic stages in the degradation of polyamide $6.6[17,19,20]$, with respective IR absorption peaks monitored at 2357, 968 and $2933 \mathrm{~cm}^{-1}$. Absorption intensities were recorded over time and normalised with respect to unit sample mass after equilibration at $100{ }^{\circ} \mathrm{C}$. Carbon dioxide profiles acquired under nitrogen and all others under air were corrected for atmospheric interference by the addition or subtraction of the lowest value of each spectral trace to give a zero baseline. The total amounts of $\mathrm{CH}_{\mathrm{x}}, \mathrm{NH}_{3}$ and $\mathrm{CO}_{2}$ produced were calculated by summing all the FTIR intensity data points in arbitrary units.

\subsection{Char Analysis}

Selected chars from cone calorimetric studies were analysed by a Thermo-Scientific Nicolet iS10 FTIR instrument in combination with a diamond lens, attenuated total reflection (ATR) adapter. Detection of key metals within selected compounded chip samples and derived chars was undertaken by X-ray Fluorescence (XRF) experiments using the facilities of William Blythe Ltd., comprising a PANalytical Axios analyser and an Omnic software suite.

\subsection{Synergistic Effectivity}

The synergistic effectivities [21] were calculated using Equation (1), where Es is the synergistic effectivity, and $X_{p}, X_{s}, X_{f r}$ and $X_{[f r+s]}$ are the measured flammability parameters LOI and the percentage reduction in cone calorimetrically determined peak heat release rate $\left(\mathrm{R}_{\mathrm{PHRR}}\right)$. These represent the respective parameters for pure PA66, PA66 containing the synergist, PA66 containing the primary PolyBrFR and PA66 containing both.

$$
\text { Es }=\left[X_{[f r+s]}-X_{p}\right] /\left[\left(X_{f r}-X_{p}\right)+\left(X_{s}-X_{p}\right)\right]
$$

\section{Results and Discussion}

\subsection{Thermogravimetric Behaviour}

Interactions between the three potential synergists (AlW, SnW and $\mathrm{ZnW}$ ) and both selected PolyBrFRs (BrPS and BrPBz) were investigated based on the experimental matrix in Table 1, in which the brominated flame retardants were fixed at $10 \mathrm{wt} . \%$ total (equivalent to bromine levels in the range 6-7 wt.\%) and the tungstates at $5 \mathrm{wt} . \%$ each. For both brominated flame retardants, selected levels were considered to not be sufficient to promote acceptably high degrees of flame retardancy on their own, so that any improvement in FR behaviour through the addition of the synergist would be clearly observed. Averaged TGA/DTA data under air is presented in Table 1 and the TGA curves from one set of TGA responses for each brominated flame retardant alone compounded in PA66 are shown in Figure 2. As can be seen, BrPBz significantly reduces the onset of degradation from $\sim 386$ to $\sim 363{ }^{\circ} \mathrm{C}$, while addition of BrPS shows a shift to a slightly higher temperatures, although subsequently showing a more rapid subsequent mass loss than either pure PA66 or BrPBz. It is evident that the presence of each PolyBrFR has significantly reduced the maximum rate loss temperatures relative to the control indicating significant interactions occurring with PA66. The effect of adding each tungstate to each PolyBrFR has little effect on the shapes of the respective TGA responses for the BrPS and BrPBz only formulations in Figure 2, with only slight shifts towards lower onset temperatures at $5 \%$ mass loss $\left(\mathrm{T}_{5 \%}\right)$ and maximum volatilization rate temperatures $\left(\mathrm{T}_{\max }\right)$, as shown in Table 1. 


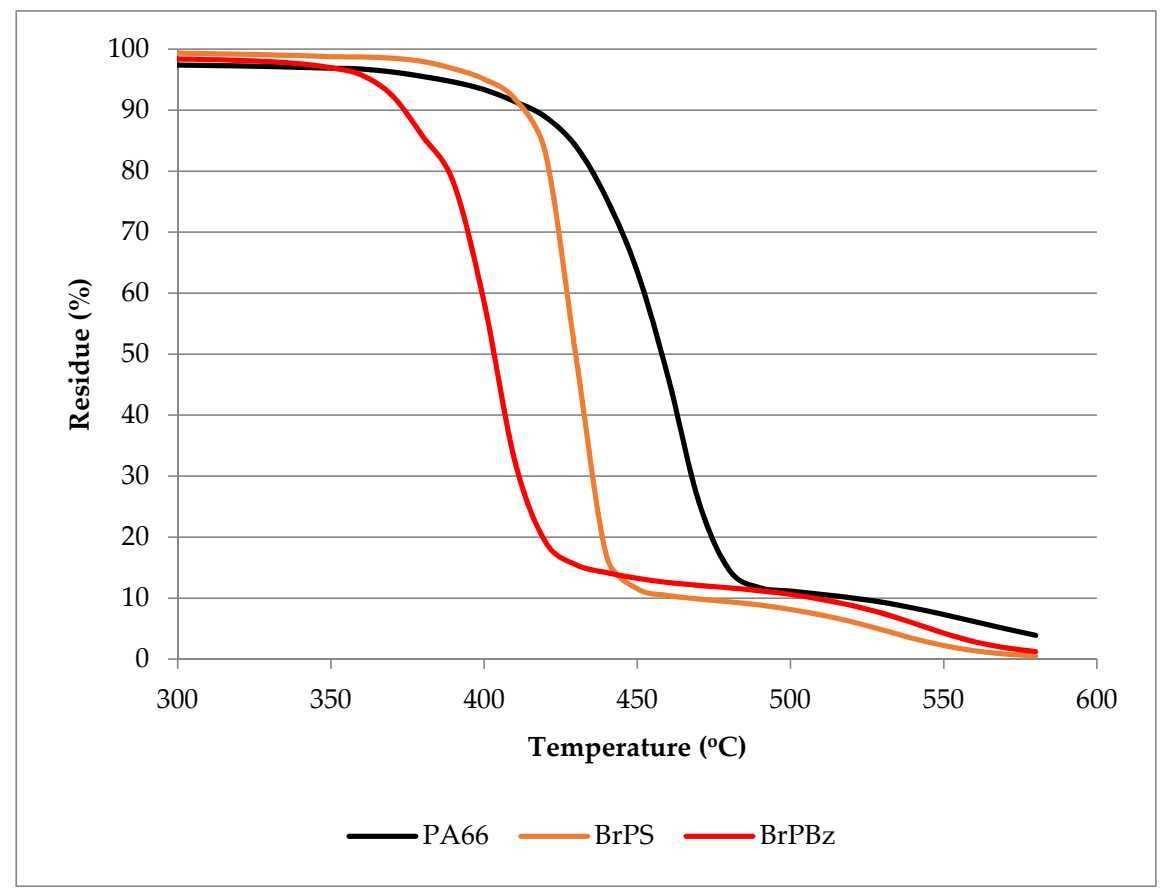

Figure 2. TGA mass losses of PA66 and PA66 samples containing $10 \mathrm{wt} . \%$ brominated polystyrene, $\mathrm{BrPS}$, and and poly(pentabromobenzyl acrylate), BrPBz, under air.

Table 1 also shows that high temperature residue yields at 500 and $580{ }^{\circ} \mathrm{C}$ in air, while little affected by the presence of each PolyBrFR alone, show variable increases which appear to be tungstate dependent. These temperatures represent the levels of maximum oxidation-sensitised char formation and its subsequent oxidation respectively [17].

After correcting each $\mathrm{R}_{500}$ value by subtraction of an assumed $5 \mathrm{wt} . \%$ tungstate presence from each (although volatile bromides and oxybromides might result from PolyBrFR-tungstate interactions), residue levels at $500{ }^{\circ} \mathrm{C}$ significantly increase only when $\mathrm{SnW}$ and $\mathrm{ZnW}$ are present, with the addition of AlW appearing to have little or no char-enhancing effect. For these two former tungstates, it would appear that they are exerting some level of condensed-phase activity in the presence of each PolyBrFR.

\subsection{Fire Performance}

The UL94 and LOI fire performance data for PA66 with BrPS and BrPBz alone are presented in the upper part of Table 2, with respective values for each tungstate alone in PA66 inserted for comparison from our previous publication [16], where it was shown that their addition at $5 \mathrm{wt} . \%$ has a slight negative effect on the LOI with respect to PA66 with little if any effect on UL94 ratings. The generally poor reproducibility of the UL94 results is considered to be caused by less-than-ideal additive dispersion achieved when using a laboratory scale compounder. It was proposed that this slight lowering of the PA66 LOI from a base value of $22.6 \mathrm{vol} . \%$ is a consequence of changes in melt dripping behaviour caused by the previously reported char-forming effect, although the effect is not as evident in the presence of AlW. While there is minimal effect on LOI again by addition of $\mathrm{BrPS}$ and BrPBz alone, UL94 performance is improved and further inclusion of either $\mathrm{SnW}$ or $\mathrm{ZnW}$ increases LOI values significantly to $>26.0 \mathrm{vol} . \%$ and improves the consistency of UL94 V-ratings with PA66-SnW-BrPS, PA66-ZnW-BrPS, and PA66-ZnW-BrPBz formulations yielding at least V-2 ratings. 
Table 2. Formulations, principal flammability parameters and derived synergistic effectivities for tungstate/zinc stannate/ATO-bromine-containing formulations in PA66.

\begin{tabular}{|c|c|c|c|c|c|c|c|c|c|c|}
\hline \multirow[t]{2}{*}{ Sample } & \multicolumn{3}{|c|}{ Composition $(\%)$} & \multicolumn{7}{|c|}{ Flammability Parameters } \\
\hline & PA66 & MC * & PolyBrFR & UL-94 *** & LOI, Vol.\% & $\mathrm{Es}_{(\mathrm{LOI})}$ & PHRR, kW/m² & TSR $\mathrm{m}^{2} / \mathrm{m}^{2}$ & R PHRR $_{\text {P }}$ & Es $_{\text {(RPHRR) }}$ \\
\hline PA66 & 100 & - & - & $\mathrm{F}$ & 22.6 & - & 1644 & 609 & - & - \\
\hline BrPS & 90 & - & 10 & $\mathrm{~V}-2 / \mathrm{V}-2 / \mathrm{F}$ & 22.9 & - & 1049 & 1821 & 36.2 & - \\
\hline $\mathrm{BrPBz}$ & 90 & - & 10 & $\mathrm{~V}-2$ & 22.3 & - & 1206 & 1447 & 26.6 & - \\
\hline $\mathrm{AlW}^{* *}$ & 95 & 5 & - & $\mathrm{V}-0 / \mathrm{V}-2 / \mathrm{F}$ & 23.0 & - & 1156 & 927 & 29.7 & - \\
\hline $\mathrm{SnW} * *$ & 95 & 5 & - & $\mathrm{F} / \mathrm{F} / \mathrm{V}-2$ & 21.5 & - & 954 & 939 & 42.0 & - \\
\hline $\mathrm{ZnW} * *$ & 95 & 5 & - & $\mathrm{F}$ & 22.0 & - & 1190 & 638 & 27.6 & - \\
\hline AlW-BrPS & 85 & 5 & 10 & $\mathrm{~V}-2 / \mathrm{V}-2 / \mathrm{F}$ & 23.3 & 1 & 999 & 1789 & 39.2 & 0.60 \\
\hline AlW-BrPBz & 85 & 5 & 10 & $\mathrm{~F} / \mathrm{F} / \mathrm{V}-2$ & 22.3 & 0 & 1174 & 1246 & 28.6 & 0.51 \\
\hline SnW-BrPS & 85 & 5 & 10 & $\mathrm{~V}-2$ & 26.7 & $>1$ & 546 & 1973 & 66.8 & 0.85 \\
\hline SnW-BrPBz & 85 & 5 & 10 & $\mathrm{~F} / \mathrm{F} / \mathrm{V}-2$ & 26.7 & $>1$ & 802 & 1766 & 51.2 & 0.75 \\
\hline ZnW-BrPS & 85 & 5 & 10 & $\mathrm{~V}-2$ & 26.2 & $>1$ & 485 & 949 & 70.5 & 1.11 \\
\hline ZnW-BrPBz & 85 & 5 & 10 & V-2/V-2/V-0 & 28.5 & $>1$ & 896 & 1186 & 45.5 & 0.84 \\
\hline PA66 $6^{* * * *}$ & 100 & - & - & F & 24.5 & - & 1359 & 569 & - & - \\
\hline BrPS **** & 85.1 & - & 14.9 & $\mathrm{~V}-2$ & 23.8 & - & 1056 & 1730 & - & - \\
\hline $\mathrm{BrPBz}^{* * * *}$ & 85.9 & - & 14.1 & $\mathrm{~V}-2$ & 23.9 & - & 990 & 1490 & 27.1 & - \\
\hline ZnS-BrPS **** & 77.8 & 7.3 & 14.9 & V-1 & 26.7 & $>1$ & 354 & 1473 & 74.0 & 1.20 \\
\hline ATO-BrPS **** & 79.0 & 6.1 & 14.9 & $\mathrm{~V}-2$ & 31.0 & $>1$ & 562 & 2794 & 58.6 & 0.88 \\
\hline $\mathrm{ZnS}-\mathrm{BrPBz}$ **** & 78.6 & 7.3 & 14.1 & $\mathrm{~V}-0$ & 28.5 & $>1$ & 163 & 969 & 88.0 & 1.32 \\
\hline ATO-BrPBz ${ }^{* * * *}$ & 79.8 & 6.1 & 14.1 & $\mathrm{~V}-2$ & 31.9 & $>1$ & 584 & 2707 & 57.0 & 0.80 \\
\hline
\end{tabular}

Notes: $\mathrm{BrPS}=$ brominated polystyrene; $\mathrm{BrPBz}=$ poly(pentabromobenzyl acrylate); AlW, SnW and ZnW = aluminium, tin (II) and zinc tungstates respectively; ${ }^{*} \mathrm{MC}$ indicates each metal compound; ** values from [16];*** a single rating indicates that all three test results achieved that value, otherwise individual test values given; $\mathrm{F}=$ fail; **** values reworked from [14], where PolyBrFR concentrations are equivalent to $10 \mathrm{wt} . \% \mathrm{Br}$; PHRR is peak heat release; TSR is total smoke release; $\mathrm{R}_{\mathrm{PHRR}} \%$ is the percentage reduction in peak heat release rate, PHRR, with respect to PA66; $\mathrm{Es}_{(\mathrm{LOI})}$ and $\mathrm{Es}_{(\mathrm{RPHRR})}$ are synergistic effectivities based on LOI and $\mathrm{R}_{\mathrm{PHRR}}$ values respectively. 
Synergistic effectivity values cannot be sensibly calculated for the LOI data due to the negative denominators produced by SnW and ZnW, which have LOI values less than the control PA66 $\left(\left(X_{s}-X_{p}\right)\right.$ see Equation (1)), leading to erroneously large negative Es values, and so in Table 2 we have assumed that $\left(X_{s}-X_{p}\right)=0$ and nominally given values $>1$ for SnW and $\mathrm{ZnW}$-containing formulations since for the AlW-BrPS formulation which shows the low LOI value of 23.3, $\mathrm{Es}_{(\mathrm{LOI})}=1$.

The cone calorimetry heat release curves for this sample set are plotted in Figure 3 . The behaviour of the cone calorimetric heat release rate curves resembles those reported previously by ourselves for tungstate/phosphorus FR formulations [17], in that times-to-ignition are reduced by the inclusion of both $\mathrm{BrPS}$ and $\mathrm{BrPBz}$, corresponding to the reduced onset of degradation temperatures in TGA presented in Table 1. The associated PHRR, $R_{P H R R}$ (the percentage reduction in PHRR), THR, and TSR values are also presented in Table 2, alongside synergistic effectivity values derived from $R_{P H R R}$ values. It is clear that, generally, BrPS-containing samples, especially those containing $\mathrm{ZnW}$ and $\mathrm{SnW}$, generate lower peak heat release rates, which are approximately $50 \%$ lower than the equivalent samples containing BrPBz. However, these respective reductions in PHRR values do not relate to the respective LOI and especially UL94 performances, as evidenced by the PA66-ZnW-BrPBz formulation that records both the highest LOI value (28.5 vol.\%) and the highest V-ratings but only a moderate $R_{P H R R}$ value. A similar non-correlation between changes in LOI and UL94 values and respective cone calorimetric data was noted in our previous study of the effect of phosphorus-containing retardant in PA66 [17]. This leads again to the conclusion that the effect of tungstate-PolyBrFR combinations influences pre-ignition-based parameters in a different manner to post-ignition parameters. This inference suggests also that the presences of $\mathrm{ZnW}$ and $\mathrm{BrPBz}$ have a greater condensed phase effect than other tungstate-PolyBrFR combinations, which is supported by the TGA data in Table 1 where the PA66-ZnW-BrPBz formulation is shown to have the highest $R_{500}$ and $R_{580}$ values.

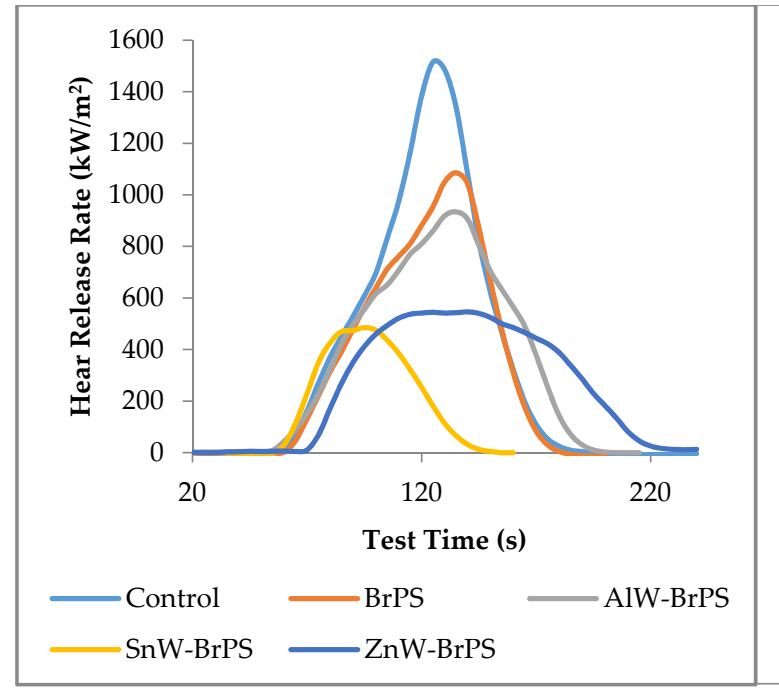

(a)

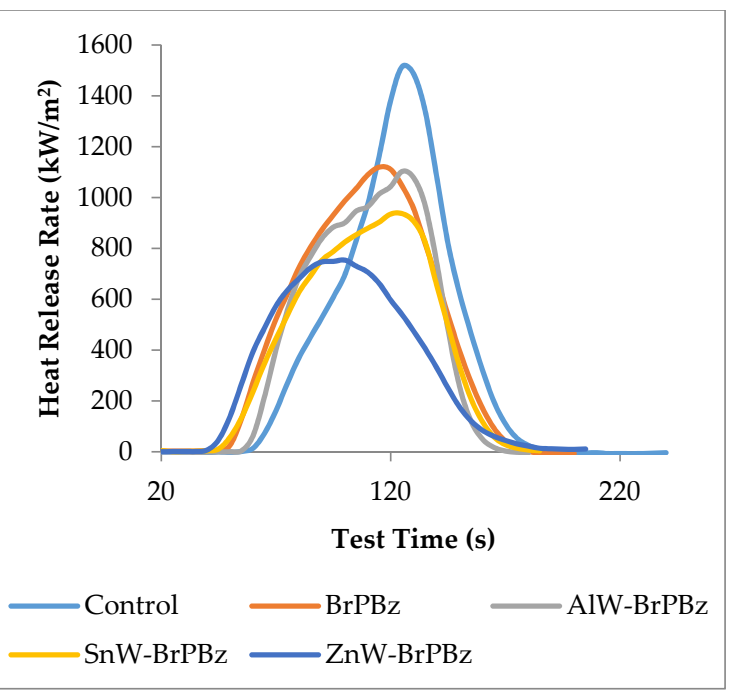

(b)

Figure 3. Cone calorimetry heat release rate curves for Table 1 samples. (a) formulations containing brominated polystyrene (BrPS) and (b) formulations containing poly(pentabromobenzyl acrylate) (BrPBz). AlW, SnW and $\mathrm{ZnW}=$ aluminium, tin (II) and zinc tungstates respectively.

The $\mathrm{Es}_{(\mathrm{RPHRR})}$ values listed in Table 2 indicate that SnW-PolyBrFR and ZnW-PolyBrFR formulations exhibit high levels of additivity, with ZnW-BrPS showing evidence of synergy (Es > 1). Therefore, it is proposed that zinc tungstate in particular might be a suitable synergist and alternative to ATO with some BrFRs. To test this hypothesis, the previously published results [14] regarding the relative effects of ATO and zinc stannate (ZnS) on BrPS and BrPBz are inserted into the lower part of Table 2 and respective $\mathrm{Es}_{(\mathrm{LOI})}$ and $\mathrm{Es}_{(\mathrm{RPHRR})}$ values calculated. The same problems arise with calculation of the 
former set of tungstate/PolyBrFR formulations with respect to LOI in that negative $\left(X_{s}-X_{p}\right)$ values are observed and so these imported samples are represented also by having values Es $>1$ assuming $\left(X_{\mathrm{s}}-\mathrm{X}_{\mathrm{p}}\right)=0$.

However, it is seen that all combinations have $\mathrm{Es}_{(\mathrm{RPHRR})}$ values either approaching unity for ATO-containing formulations and $>1$ for ZnS-containing formulations. By comparing these values with those for the respective SnW- and $\mathrm{ZnW}$-containing formulations, it may be concluded that both tungstates are functioning in a synergistic capacity. With regard to smoke formation, while the addition of either PolyBrFR alone increases TSR values considerably with respect to PA66 as expected, the addition of each tungstate apart from SnW shows a general tendency for significant reductions. The smoke results plotted as percentage changes in TSR caused by addition of each tungstate, zinc stannate or ATO compared to the respective PA66-PolyBrFR sample ( $\triangle \mathrm{TSR} \%)$ are presented in Figure 4 for each set of PolyBrFR combinations. Not surprisingly, the formulations containing ATO as the synergist show significant increases in smoke generation with only SnW behaving in a similar but much less severe manner. In contrast, the well-documented smoke suppressing property of zinc stannate, in the presence of each PolyBrFR is evident [12]. However, the greatest reduction in TSR is observed when $\mathrm{ZnW}$ is in the presence of either BrPS or BrPBz, which suggests that $\mathrm{ZnW}$ is comparable to zinc stannate as a smoke suppressant. It is interesting to note that the effectiveness of $\mathrm{ZnW}$ compared to $\mathrm{ZnS}$ with the two PolyBrFRs investigated is reversed, in that, $\mathrm{ZnW}$ is the more effective smoke suppressant with BrPS, while $\mathrm{ZnS}$ is the more effective with BrPBz.

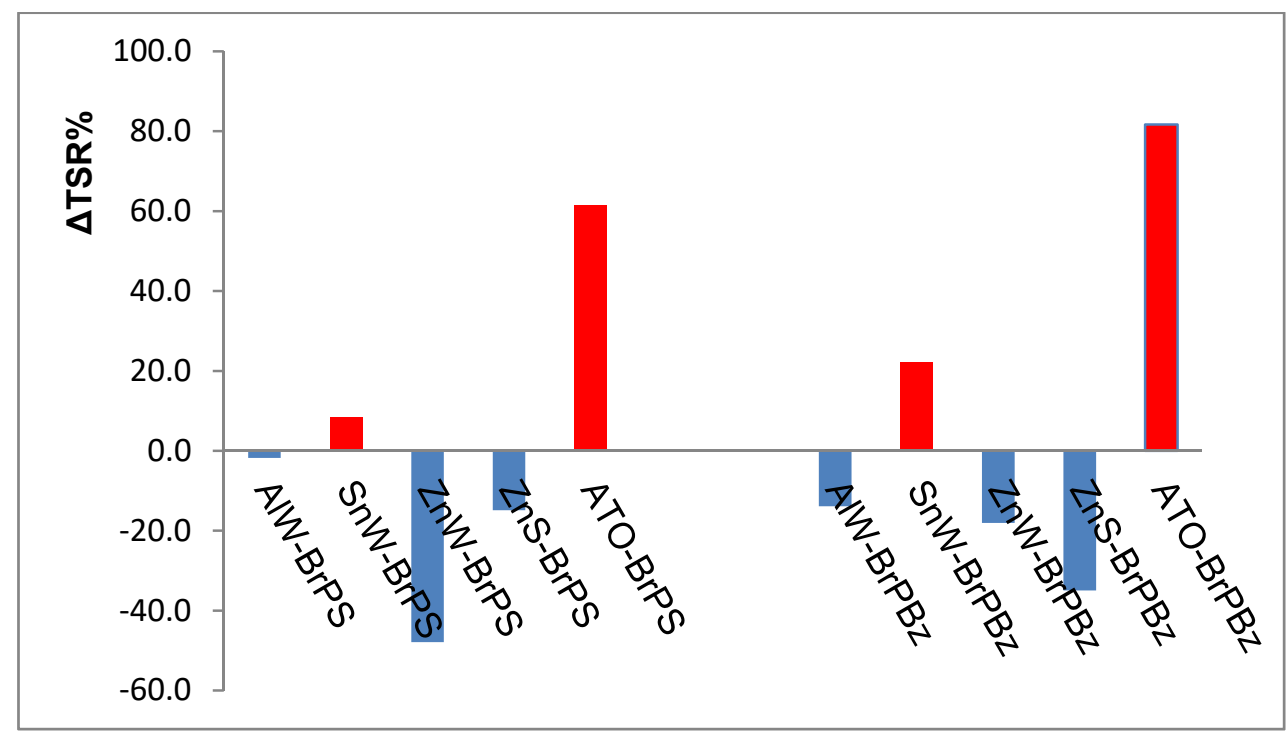

Figure 4. Percentage changes in smoke generation where the percentage change in total smoke release, $\Delta \mathrm{TSR} \%=\left[\mathrm{TSR}_{(\mathrm{MC} / \mathrm{PolyBrFR})} / \mathrm{TSR}_{(\mathrm{PolyBrFR})}-1\right] \times 100$ and $\mathrm{TSR}_{(\mathrm{MC} / \mathrm{PolyBrFR})}$ and $\mathrm{TSR}_{(\mathrm{PolyBrFR}}$ are the respective smoke release values for each metal compound (MC) in combination with each PolyBrFR and PolyBrFR alone in PA66: Red columns indicate an increase and blue columns a decrease in smoke generation with respect to that from either brominated polystyrene, BrPS, or poly(pentabromobenzyl acrylate), BrPBz, present in PA66 alone. AlW, SnW and $\mathrm{ZnW}=$ aluminium, tin (II) and zinc tungstates respectively; $\mathrm{ATO}=$ antimony (III) oxide and $\mathrm{ZnS}=$ zinc stannate.

\subsection{TGA-FTIR Evolved Gas Analysis}

The thermal degradation of polyamide 6.6 is more complex than that of the other aliphatic polyamides, primarily because chain scission combined with the elimination via ring formation of cyclopentanone, are precursors to cross-linking reactions [20]. In addition to the review by Schaffer et al. [20], we previously reviewed the thermal degradation mechanism of polyamide 6.6, including the majority of significant published work from the 1950-1960 period [17,19] from which the following volatile species identifiable by FTIR are used as mechanistic indicators. 
Carbon dioxide is considered to be a product of polyamide chain scission, cyclopentanone and other fuel species, together designated as $\mathrm{CH}_{\mathrm{x}}$, are evolved primary flammable volatiles and ammonia, produced primarily by condensation reactions, is an indicator of the formation of precursors to char-formation. These species were monitored during TGA using FTIR, namely $\mathrm{CO}_{2}$ at $2357 \mathrm{~cm}^{-1}$, aliphatic fuel formers (including cyclopentanone) $\mathrm{CH}_{\mathrm{x}}$ at $2933 \mathrm{~cm}^{-1}$, and $\mathrm{NH}_{3}$ at $968 \mathrm{~cm}^{-1}$.

Compounded specimens containing SnW and $\mathrm{ZnW}$ with associated controls were selected from the sample matrix presented in Table 1 and subjected to TGA-FTIR evolved gas analysis under both air and nitrogen. Samples containing AlW were omitted since these possessed the lowest flame retardancy from the results in Table 2. Exemplar FTIR spectra are shown in Figure 5 for the PA66 control and the $\mathrm{ZnW}$-BrPS sample under air. In all spectra the peaks for $\mathrm{CH}_{\mathrm{x}}\left(2933 \mathrm{~cm}^{-1}\right), \mathrm{CO}_{2}\left(2357 \mathrm{~cm}^{-1}\right)$ and $\mathrm{NH}_{3}\left(968 \mathrm{~cm}^{-1}\right)$ are significantly evident with no signs of either a carbon monoxide or CO doublet at 2100 and $2200 \mathrm{~cm}^{-1}$ or, in the PA66/BrPS (and PA66/PPBz) samples, $\mathrm{HBr} P$ and R IR bands at 2500 and $2600 \mathrm{~cm}^{-1}$, possibly due to reactions of $\mathrm{HBr}$ with the heated stainless steel gas line. Furthermore, it might be expected that other toxic species such as $\mathrm{HCN}$ (absorbing at $\sim 2100 \mathrm{~cm}^{-1}$ ) would be produced in the presence of PolyBrFRs [22], and its absence here could also be a consequence of its reaction within the transfer line. The cyclopentanone $\mathrm{C}=\mathrm{O}$ stretch absorption at $1750 \mathrm{~cm}^{-1}$ is also evident, though some overlap with other species present meant that this was not suitable for monitoring directly.

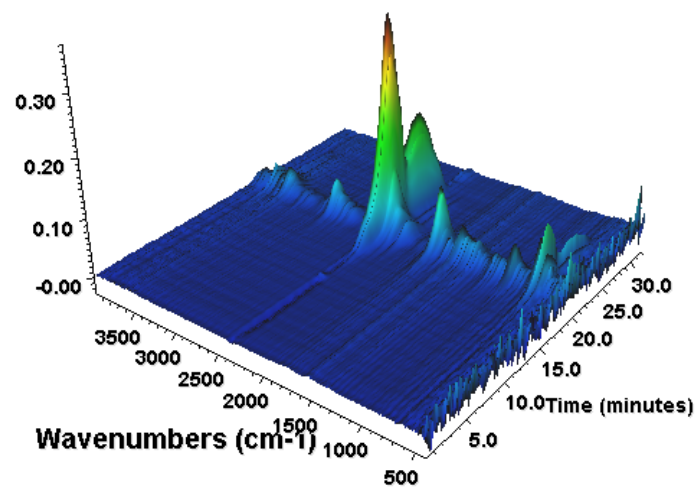

(a)

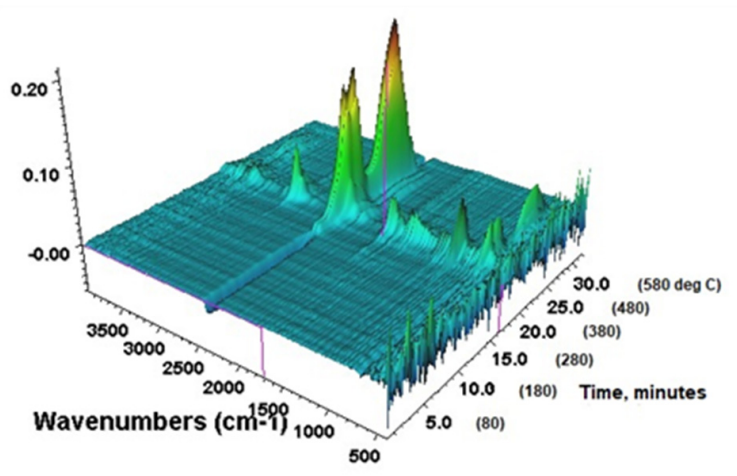

(b)

Figure 5. Exemplar 3D plots of TGA-FTIR data for (a) pure PA66 and (b) ZnW-BrPS under air.

The $\mathrm{CH}_{\mathrm{x}}\left(2933 \mathrm{~cm}^{-1}\right), \mathrm{CO}_{2}\left(2357 \mathrm{~cm}^{-1}\right)$ and $\mathrm{NH}_{3}\left(968 \mathrm{~cm}^{-1}\right)$ peak intensities as a function of temperature for all samples are shown in Figure 6. While the TGA responses in Figure 2 have typically shown that the thermal degradation of PA66 appears to be a single transition, the evolution of the different species occurring at different temperatures demonstrates the underlying complexity of the various reactions taking place $[17,19,20,23]$. Our recently published work regarding polyamide 6 thermal degradation showed that TGA responses for may in fact be resolved if high heating rates are used, thereby demonstrating that underlying reactions occur at differing rates [24].

The areas (A) under each of the respective gas/volatile evolution intensity versus temperature plots in Figure 6 were recorded and then normalised with respect to the respective PA66 control values under both nitrogen and air atmospheres, and results are presented in Table 3 . These results are expressed with respect to the PA66 control $(\mathrm{A}=1.00)$ as differential bar charts $(\mathrm{A}-1.00)$ in Figure 7 . It should be noted that volatile emissions recorded above $580^{\circ} \mathrm{C}$, notably in Figure 6 a for carbon dioxide emission from the $\mathrm{ZnW}-\mathrm{BrPBz}$ formulation, is the ratio of the latter high residue $\left(\mathrm{R}_{580}=20.8 \%\right.$-see Table 1$)$ relative to the much lower value of the control (3.9\%). 


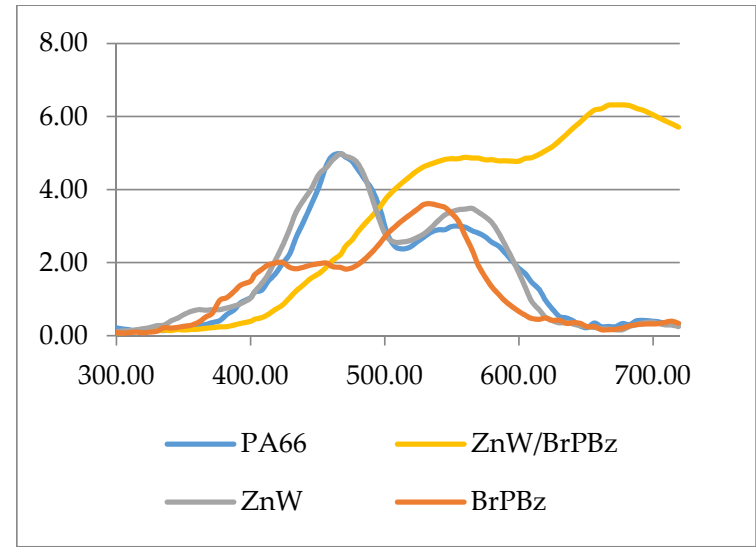

(a) $\mathrm{CO}_{2} / \mathrm{air}$

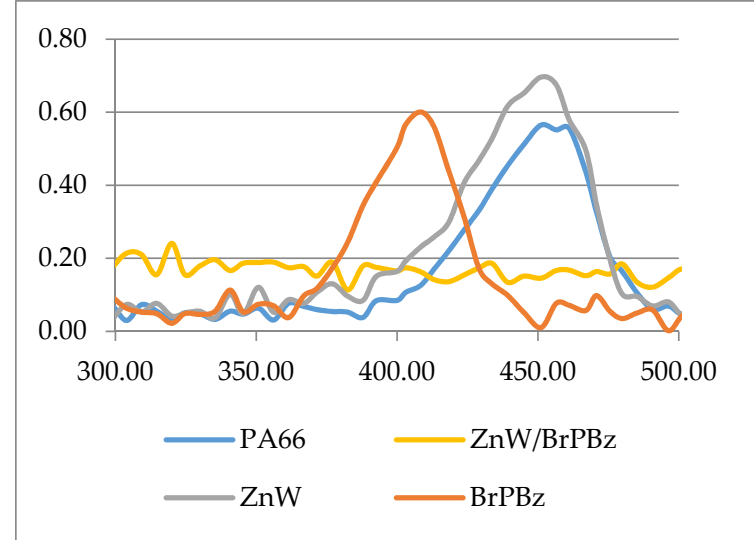

(c) $\mathrm{NH}_{3} / \mathrm{air}$

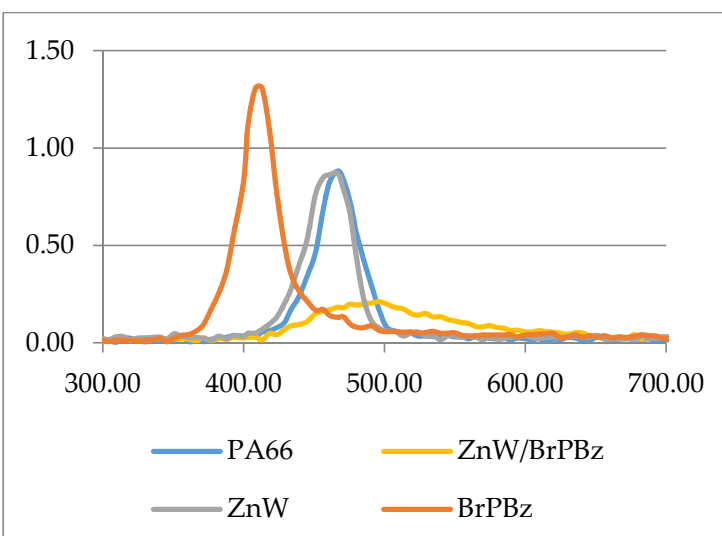

(e) $\mathrm{CH}_{x} /$ air

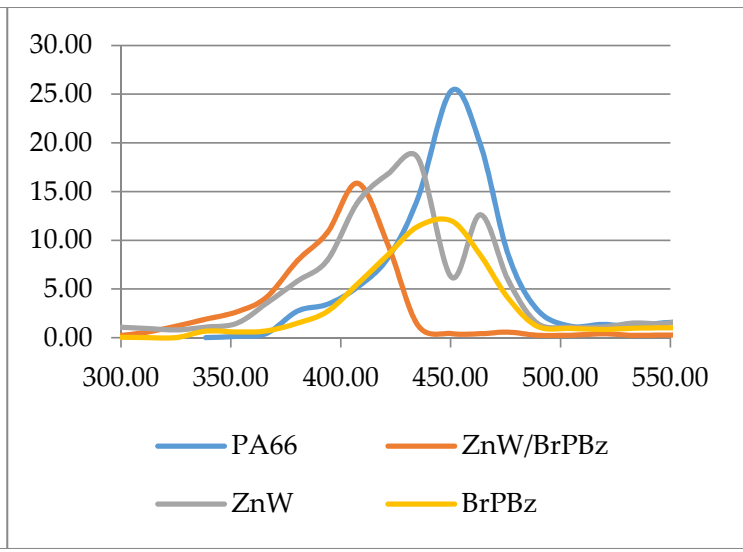

(b) $\mathrm{CO}_{2} / \mathrm{N}_{2}$

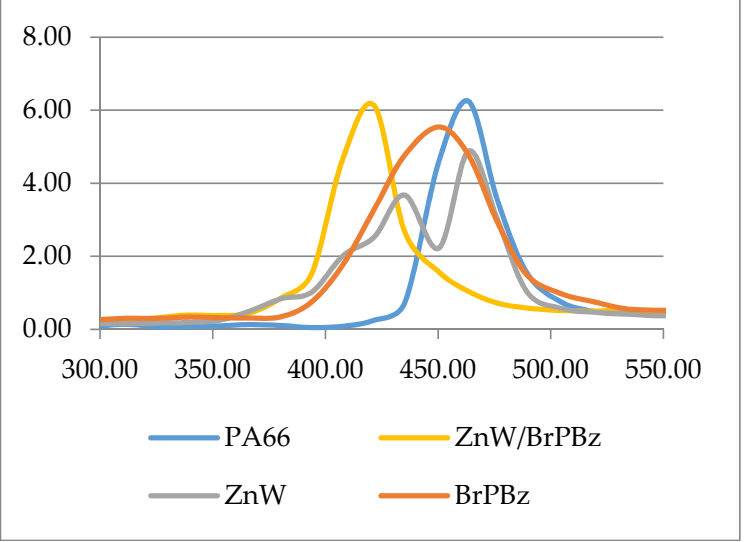

(d) $\mathrm{NH}_{3} / \mathrm{N}_{2}$

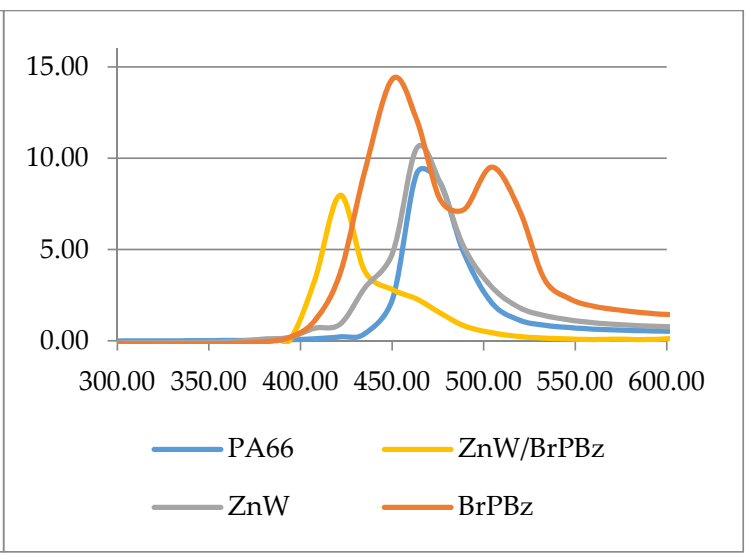

(f) $\mathrm{CH}_{x} / \mathrm{N}_{2}$

Figure 6. Plots of the intensity of $\mathrm{CO}_{2}, \mathrm{NH}_{3}$ and $\mathrm{CH}_{\mathrm{x}}$ evolution for $\mathrm{ZnW}$ formulations with/without brominated polystyrene, BrPS, and poly(pentabromobenzyl acrylate), $\mathrm{BrPBz}$, as measured by FTIR versus TGA temperature under air and nitrogen, respectively; $\mathrm{CO}_{2}(\mathbf{a}, \mathbf{b}), \mathrm{NH}_{3}(\mathbf{c}, \mathbf{d}), \mathrm{CHx}(\mathbf{e}, \mathbf{f})$. Note that the temperatures here do not account for the approximate $45 \mathrm{~s}$ delay in recording the FTIR signal. $\mathrm{SnW}$ and $\mathrm{ZnW}=$ tin (II) and zinc tungstates respectively. 
Table 3. TGA-FTIR gas/volatile absorption intensities (A) collected under air and $\mathrm{N}_{2}$, normalised to respective pure PA66 values $(\mathrm{A}=1.00)$. The compositions of these samples correspond to those in Tables 1 and 2 . Those samples marked with an asterix $\left(^{*}\right)$ have the best fire performance.

\begin{tabular}{|c|c|c|c|c|c|c|}
\hline Sample & $\begin{array}{l}\mathrm{CO}_{2} \\
\text { (Air) }\end{array}$ & $\begin{array}{l}\mathrm{CO}_{2} \\
\left(\mathrm{~N}_{2}\right)\end{array}$ & $\begin{array}{l}\mathrm{NH}_{3} \\
\text { (Air) }\end{array}$ & $\begin{array}{l}\mathrm{NH}_{3} \\
\left(\mathrm{~N}_{2}\right)\end{array}$ & $\begin{array}{l}\mathrm{CH}_{\mathrm{x}} \\
\text { (Air) }\end{array}$ & $\begin{array}{l}\mathrm{CH}_{x} \\
\left(\mathrm{~N}_{2}\right)\end{array}$ \\
\hline Control & 1.00 & 1.00 & 1.00 & 1.00 & 1.00 & 1.00 \\
\hline BrPS & 0.76 & 0.33 & 1.27 & 1.01 & 1.24 & 1.24 \\
\hline $\mathrm{BrPBz}$ & 0.77 & 0.63 & 0.97 & 1.58 & 1.43 & 2.54 \\
\hline $\mathrm{ZnW}$ & 1.06 & 0.92 & 1.16 & 1.24 & 1.11 & 1.34 \\
\hline SnW & 1.04 & 1.30 & 1.55 & 2.03 & 1.26 & 1.87 \\
\hline SnW-BrPS & 1.06 & 1.05 & 1.21 & 2.24 & 1.34 & 1.50 \\
\hline SnW-BrPBz & 1.09 & 0.73 & 2.01 & 2.37 & 1.51 & 1.59 \\
\hline $\mathrm{ZnW}$-BrPS * & 1.06 & 0.92 & 1.28 & 1.75 & 1.32 & 0.55 \\
\hline $\mathrm{ZnW}-\mathrm{BrPBz}$ * & 1.91 & 0.50 & 1.73 & 1.28 & 0.77 & 0.28 \\
\hline
\end{tabular}

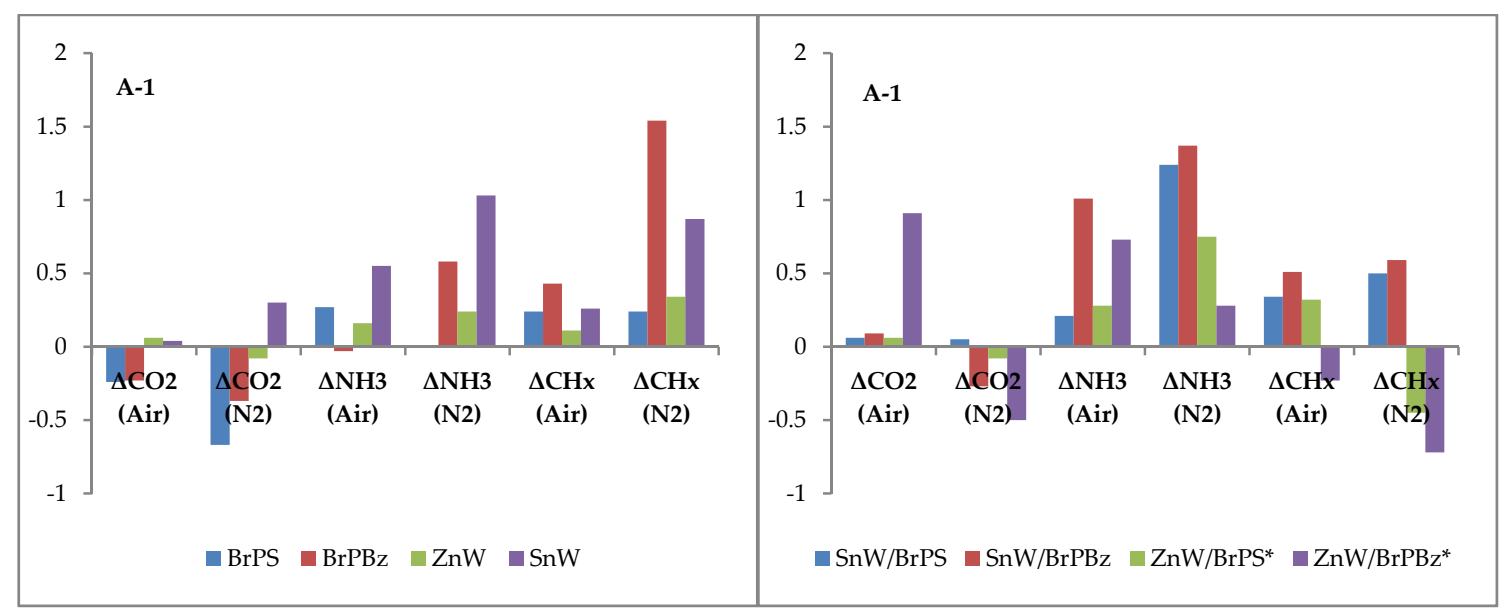

(a)

(b)

Figure 7. Variations in TGA-FTIR production of $\mathrm{CO}_{2}, \mathrm{NH}_{3}$, and $\mathrm{CH}_{\mathrm{x}}$ by the samples listed in Table 3 relative to pure PA66 and plotted as (A-1.00, see Table 3) (a) BrPS, BrPBz, ZnW and SnW controls, (b) combinations of $\mathrm{ZnW}$ and $\mathrm{SnW}$ with BrPS and BrPBz in PA66. Negative values represent a reduction in gas/volatile production, while positive values represent increases relative to the control. $\mathrm{BrPS}=$ brominated polystyrene; $\mathrm{BrPBz}=$ poly(pentabromobenzyl acrylate); $\mathrm{SnW}$ and $\mathrm{ZnW}=\mathrm{tin}$ (II) and zinc tungstates respectively.

Referring to Figure 7, both PolyBrFRs alone reduce the $\mathrm{CO}_{2}$ production of PA66 under both air and nitrogen, which most likely reflects their ability to reduce volatile oxidation in the vapour phase. BrPS increases $\mathrm{NH}_{3}$ production under air, while BrPBz increases it under $\mathrm{N}_{2}$ and both PolyBrFRs and especially $\mathrm{BrPBz}$ increase the production of flammable volatiles $\left(\mathrm{CH}_{\mathrm{x}}\right)$ under both atmospheres. Combined with the other observations, this would suggest that any $\mathrm{HBr}$ formed during degradation of these compounds, although not observed for reasons stated above, would both alter the mechanism of and accelerate the degradation of PA66 [17], corresponding to the graphical data presented in Figure 2 and Table 1 and sensitisation of PA66 degradation by each PolyBrFR. The effects of inert and oxidising atmospheres on the subsequent degradation mechanisms of PA66 are complex, as numerous oxidation products behave somewhat differently than when heated under inert degradative conditions as evidenced by increased char formation, for example [13,17].

$\mathrm{ZnW}$ alone has relatively minimal effects on the degradation products of PA66 under either atmosphere, while $\mathrm{SnW}$ markedly increases both $\mathrm{NH}_{3}$ and $\mathrm{CH}_{\mathrm{x}}$ production, especially under an inert atmosphere. The condensed-phase interactions of PA66 and its degradation products with inorganic 
additives often stem from Lewis-acid catalysis of these processes and there is evidence that $\mathrm{SnW}$ is more powerful than $\mathrm{ZnW}$ in this respect $[17,25]$.

$\mathrm{CO}_{2}$ production is affected little by the combined SnW-PolyBrFR compositions under either atmosphere, though both $\mathrm{NH}_{3}$ and $\mathrm{CH}_{\mathrm{x}}$ production are increased, which are especially notable in the SnW-BrPBz formulation in air. This formulation also has an inferior performance and $R_{P H R R}$ value compared with the SnW-BrPS formulation, although char levels at $500{ }^{\circ} \mathrm{C}$ and LOI values are similar for both (Tables 1 and 2).

The ZnW-PolyBrFR samples display differing behaviour depending upon which PolyBrFR is present. The $\mathrm{ZnW}$-BrPS formulation relative to the PA66 control has minimal effect on $\mathrm{CO}_{2}$ production and increases $\mathrm{NH}_{3}$ release under both conditions and while increasing $\mathrm{CH}_{\mathrm{x}}$ production under air, reduces it under $\mathrm{N}_{2}$. This moderate increase in $\mathrm{CH}_{x}$ and, hence, flammable volatile production in air is perhaps partly reflected in this sample's increased LOI (26.2 vol\%) value, although its high $R_{P H R R}$ $(70.5 \%)$ values in Table 2 provides evidence of a post-ignition, synergistic system $\left(\operatorname{Es}_{(\mathrm{RPHRR})}=1.11\right)$. However, cyclopentanone is a significant component of the $\mathrm{CH}_{\mathrm{x}}$ fuel fraction and this is known to promote cross-linking and eventual char formation, which could influence burning behaviour $[19,20]$.

The ZnW-BrPBz composition diverges significantly from the control and samples containing either $\mathrm{ZnW}$ or $\mathrm{BrPBz}$ alone. $\mathrm{CO}_{2}$ production is increased under air and while reduced significantly under $\mathrm{N}_{2}$, is combined with an increase in $\mathrm{NH}_{3}$ evolution under both atmospheres and a substantial drop in production of flammable volatiles, especially under $\mathrm{N}_{2}$. The high $\mathrm{R}_{500}$ value $(21.2 \%$, Table 1$)$ for this formulation and its subsequent combustion have been proposed as the cause of this increased $\mathrm{CO}_{2}$ production as noted above with reference to Figure 6a. The parallel increase in $\mathrm{NH}_{3}$ evolution may also be related to this high level of char formation, although the low $R_{P H R R}$ value $(45.5 \%$, Table 2$)$ and derived synergistic effectivity, $\mathrm{Es}_{(\mathrm{RPHRR})}$, of 0.84 suggests reduced post-ignition activity of the ZnW-BrPBz system compared with it superior pre-ignition activity in terms of the highest LOI ( $28.5 \mathrm{vol} \%)$ and $>\mathrm{V}-2$ rating achieved of all the formulations studied.

From these results it can be concluded that, in addition to the vapour-phase activity normally associated with brominated flame retardants, further condensed-phase processes must also be occurring, especially for the $\mathrm{ZnW}-\mathrm{BrPBz}$ sample. The high $\mathrm{R}_{500}$ and $\mathrm{R}_{580}$ values in Table 1 again confirm this inference.

The mechanism of smoke suppression produced by $\mathrm{ZnW}$ in the presence of $\mathrm{BrPS}$ or BrPBz remains poorly understood, although it could be attributed to the action of generated Lewis acids, such as $\mathrm{ZnBr}_{2}$ acting upon the precursor stages of smoke particle formation. In our related study of the effect of tungstates in combination with phosphorus-containing flame retardants in PA66 [17], while ZnW did not show any improvement in flame retardancy, it did show significant smoke suppressing properties, again associated with its probable Lewis acidic properties. It also is noteworthy that other recent work in our laboratories [26] has reported that zinc stannate in combination with BrPBz in PA66 does not show the expected significant vapour phase activity. It has previously been assumed that $\mathrm{ZnS}$ in combination with PolyBrFRs generally function by vapour phase mechanisms involving formation of volatile tin (II) bromide, tin (II) oxide and interactions between the latter and released bromine and hydrogen radicals $[11,27]$. However, this recent study has demonstrated that a considerable amount of bromine is trapped within the char that would otherwise be released into the vapour phase and that the interaction of bromine is primarily with zinc present in $\mathrm{ZnS}$ and not with tin.

\subsection{Char Analyses}

In addition to the TGA-FTIR analysis carried out as described above, char analysis of retained cone calorimetric residues was also undertaken using FTIR and XRF to allow for determination of the organic and inorganic components present. Several of the compositions tested by cone calorimetry left no residue at all, namely the PA66, BrPS and BrPBz controls and, as such, these could not be analysed. 


\subsubsection{FTIR Analysis}

The char spectra are typified by those in Figure 8 derived from cone calorimetric chars from $\mathrm{ZnW}, \mathrm{ZnW}$-BrPS and $\mathrm{ZnW}-\mathrm{BrPBz}$ formulations. These are generally characterised by carbon-hydrogen absorptions of a largely aromatic char structure, and spectra for the AlW, SnW and $\mathrm{ZnW}$ control chars contain few intense peaks, with only weak shoulder absorbances at $1200 \mathrm{~cm}^{-1}$. SnW in combination with either BrPS or BrPBz produces similar spectra, with strong absorbances observed at 2940 and $2850 \mathrm{~cm}^{-1}$, which correspond to aromatic $\mathrm{C}-\mathrm{H}$ stretch modes. Aromatic ring-flexing peaks are present at 1500-1450 $\mathrm{cm}^{-1}$, although these are far sharper than the broad peaks observed for the phosphorus-containing samples previously reported [17]. While the observed spectrum for the $\mathrm{ZnW}$-BrPS char is comparable to that of the SnW-PolyBrFR sample chars, the ZnW-BrPBz char spectrum is distinctly different from the other three bromine-containing formulations. A coherent char was produced by this sample noted previously from TGA studies (Table 2), and the FTIR spectrum of this in Figure 8 is devoid of intense peaks unlike the other formulations tested suggesting it is highly carbonaceous.

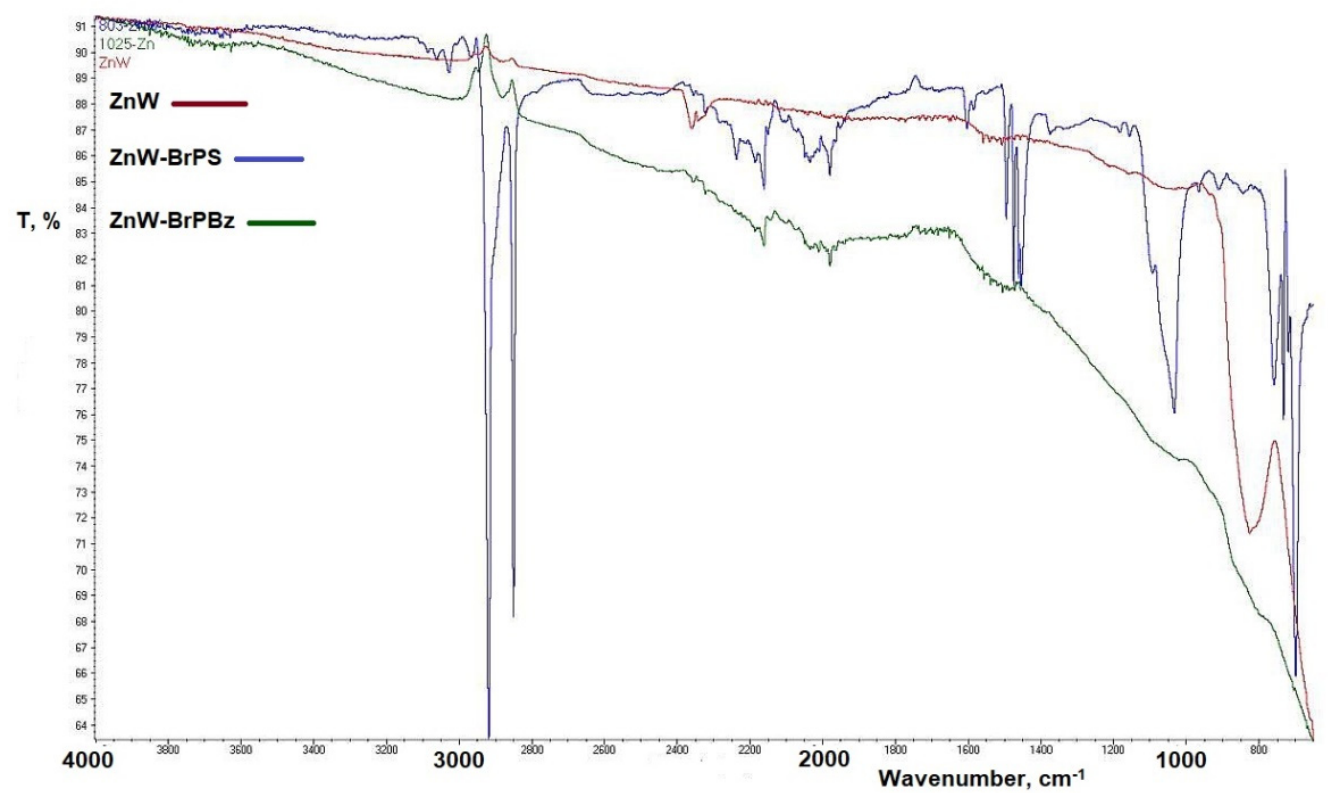

Figure 8. FTIR char spectra as percentage transmission (T\%) derived from $\mathrm{ZnW}, \mathrm{ZnW}$-BrPS and $\mathrm{ZnW}-\mathrm{BrPBz}$ formulation chars. $\mathrm{ZnW}=$ zinc tungstate; $\mathrm{BrPS}=$ brominated polystyrene; $\mathrm{BrPBz}=$ poly(pentabromobenzyl acrylate).

\subsubsection{XRF Analysis}

Chars from all Br-containing compositions were examined by XRF analysis and results are presented as ratios between the key elements (i.e., $\mathrm{M}: \mathrm{W}: \mathrm{Br}$ and $\mathrm{M}: \mathrm{W}: \mathrm{P}$, where $\mathrm{M}=\mathrm{Sn}$ or $\mathrm{Zn}$ ), as elements lighter than $\mathrm{Na}$ are not readily detected. Al could not be accurately measured as the chars were supported on aluminium foil. These results enabled comparison with the theoretical ratios calculated from the starting composition of each sample to determine which elements had been retained in the char, and which were lost to the vapour phase (see Table 4). 
Table 4. Summary of the absolute molar ratios between heavy elements in PA66 plaques and char samples normalised with respect to tungsten present in all samples $(\mathrm{W}=1.000)$. BrPS = brominated polystyrene; $\mathrm{BrPBz}=$ poly(pentabromobenzyl aacrylate); $\mathrm{SnW}$ and $\mathrm{ZnW}=$ tin (II) and zinc tungstates respectively.

\begin{tabular}{ccc}
\hline Sample & Br:W & Sn/Zn:W \\
\hline SnW/BrPS plaque & 7.532 & 1.000 \\
Char & 0.040 & 0.673 \\
SnW-BrPBz plaque & 6.796 & 1.000 \\
Char & 0.053 & 0.638 \\
ZnW-BrPS plaque & 7.046 & 1.000 \\
Char & 0.368 & 0.284 \\
ZnW-BrPBz plaque & 3.842 & 1.000 \\
Char & 0.210 & 0.179 \\
\hline
\end{tabular}

For all tungstate/PolyBrFR samples compositions tested (SnW-BrPS, SnW-BrPBz, ZnW-BrPS and $\mathrm{ZnW}-\mathrm{BrPBz}$ ), loss of bromine to the vapour phase is clearly evident, as shown by a clear reduction in the Br:W molar ratios. Losses of $\mathrm{Zn}$ and $\mathrm{Sn}$ are also observed with the former being significantly greater. However, the higher $\mathrm{Br}: \mathrm{W}$ ratios for the $\mathrm{ZnW}$-containing samples would suggest that more $\mathrm{Br}$ is retained in the condensed phase combination with the former than with SnW-containing formulations. This would suggest not only that respective metal/bromine losses to the volatile phase are not simply related, but also that condensed phase activity of $\mathrm{ZnW}$ is significant in its role as a synergist, especially with brominated polystyrene.

\section{Conclusions}

When present alone in PA66, both BrPS and BrPBz show little increases in char formation, as would be expected for these vapour phase active FRs, combined with their relatively low LOI values in the 22-23 vol.\% range, and matched with UL94 ratings which average just less than V-2. In the presence of PolyBrFRs, only $\mathrm{ZnW}$ and SnW show significant increases in LOI ( $>26$ vol.\%), with both $\mathrm{ZnW}-\mathrm{BrPS}$ and $\mathrm{ZnW}-\mathrm{BrPBz}$ formulations yielding average UL94 ratings $\geq \mathrm{V}-2$ and corrected TGA char residues at $500{ }^{\circ} \mathrm{C}$ in air $>15 \mathrm{wt} . \%$ in the decreasing order $\mathrm{ZnW}>\mathrm{SnW}>>$ AlW (see Table 1). This tungstate-PolyBrFR char-promoting effect is in the reverse order with respect to that for tungstate Lewis acidity $[17,24]$, but corresponds to the respective decreasing boiling point order and thus volatility of the metal bromides in question, namely $\mathrm{ZnBr}_{2}\left(\mathrm{BPt} .=697^{\circ} \mathrm{C}\right), \mathrm{SnBr}_{2}\left(\mathrm{BPt} .=639^{\circ} \mathrm{C}\right)$ and $\mathrm{AlBr}_{3}\left(\mathrm{BPt} .=255^{\circ} \mathrm{C}\right)$. This mirrors the effects in our previous publication, where zinc stannate was demonstrated to have greater flame retarding efficacy than antimony trioxide (via $\mathrm{SbBr}_{3}$ formation, BPt. $=288^{\circ} \mathrm{C}$ ), most likely for a similar reason (see also Table 2) [13]. The possible effects of the poorly-characterised volatile tungsten oxybromides remain to be quantified, and would require the separate study of $\mathrm{SnO}, \mathrm{ZnO}$ and $\mathrm{WO}_{3}$ in similar systems to those investigated here.

TGA-FTIR evolved gas data shows that both $\mathrm{ZnW}$ and $\mathrm{SnW}$ produce the greater changes in $\mathrm{CO}_{2}$, $\mathrm{NH}_{3}$ and $\mathrm{CH}_{\mathrm{x}}$ profiles in air with respect to the controls containing each component alone. However and as noted above, the $\mathrm{ZnW}$-BrPBz sample in air has evolved a significantly higher $\mathrm{CO}_{2}$ concentration relative to the $\mathrm{SnW}-\mathrm{BrPBz}$ sample, most likely a consequence of elevated levels of char oxidation. This coupled with the reduced $\mathrm{CH}_{\mathrm{x}}$ evolution could explain the superior flame retardancy of this latter sample where ignition and thermal resistance are the common underlying features of TGA, LOI and UL94 test procedures. In terms of reaction-to-fire behaviour and in particular comparison of PHRR values, the relative effects of $\mathrm{SnW}$ and $\mathrm{ZnW}$ show similarly higher percentage reductions when in combination with BrPS ( $\mathrm{R}_{\mathrm{PHRR}}=67$ and $71 \%$, respectively, Table 2$)$ than in combination with BrPBz $\left(R_{\text {PHRR }}=51\right.$ and $\left.46 \%\right)$. Coupled with the cone calorimetric char analyses, which suggest that $\mathrm{ZnW}$ shows greater evidence of condensed phase activity than $\mathrm{SnW}$, these figures also suggest that the effects of flame suppression by both SnW- and ZnS-PolyBrFR combinations are generally similar once ignition has occurred. 
To more fully understand the tungsten-bromine interactions involved would require further analysis beyond the scope of this present work. Suffice it to say that the effects of in-situ formation of and/or relative volatilities of possible intermediates and products, such as $\mathrm{ZnO}$ and $\mathrm{SnO}$, and the volatile bromides mentioned above, plus the possible inclusion of $\mathrm{SnBr}_{4}\left(\mathrm{BPt} .=205^{\circ} \mathrm{C}\right)$ and $\mathrm{WBr}_{6}$ $\left(\mathrm{BPt} .=327^{\circ} \mathrm{C}\right)$ and respective possible oxyhalides, may also be part of the explanation. Multicomponent analysis of the mixed-metal $(\mathrm{M})$ tungstates $\left(\mathrm{MWO}_{4} / \mathrm{M}_{2}\left(\mathrm{WO}_{4}\right)_{3}\right)$ and the separate oxides $\left(\mathrm{WO}_{3}, \mathrm{M}_{2} \mathrm{O}_{3}\right.$ and $\mathrm{MO}$ ) would be required to determine further mechanistic intricacies of the interactions between PolyBrFRs and the compounds investigated here.

In summary, $\mathrm{ZnW}$ has demonstrated excellent smoke suppression properties, particularly in combination with BrPS, and this is most likely a consequence of its significant Lewis acidic, condensed phase activity, as evidenced by the char analytical results in particular. Clearly, this work has demonstrated that zinc tungstate acts both as a flame retardant synergist and smoke suppressant with both brominated polymers, BrPS and BrPBz. Whether or not these dual characteristics are observed when $\mathrm{ZnW}$ is in combination with other BrFRs requires further research in addition to further investigations into the mechanisms underlying its activity.

Author Contributions: Conceptualization, A.F.H., B.K.K., and A.R.H.; methodology, A.F.H., B.K.K., and A.R.H.; validation, A.F.H. and A.R.H.; formal analysis, A.F.H. and A.R.H.; investigation, A.F.H.; resources, B.K.K. and A.R.H.; data curation, A.F.H.; writing—original draft preparation, A.F.H. and A.R.H.; writing — review and editing, A.F.H., B.K.K., and A.R.H.; visualization, A.F.H.; supervision, B.K.K. and A.R.H.; project administration, B.K.K. and A.R.H.; funding acquisition, B.K.K. and A.R.H. All authors have read and agreed to the published version of the manuscript.

Funding: This research was funded by the EPSRC and William Blythe Ltd. as a CASE Studentship, grant number 1001167.

Acknowledgments: We wish to thank G. J. Milnes and G. Smart, A. Zarei and S. Shafiee for their technical support. We would additionally like to thank William Blythe Ltd. and their developmental and analytical staff for their assistance and access to equipment.

Conflicts of Interest: The authors declare no conflict of interest. The funders had no role in the design of the study; in the collection, analyses, or interpretation of data; in the writing of the manuscript, or in the decision to publish the results.

\section{References}

1. McAllister, D.L. Brominated Flame Retardants: Current Issues and Future Prospects. In Proceedings of the Flame Retardants '92, London, UK, 19-20 May 1992; Interscience Communications: London, UK, 1992; pp. 149-155.

2. Wakelyn, P.J. Advances in Fire Retardant Materials; Horrocks, A.R., Price, D., Eds.; Woodhead Publishing: Cambridge, UK, 2008; pp. 188-212.

3. Horrocks, A.R. Flame retardant and environmental issues. In Update on Flame Retardant Textiles: State of the Art, Environmental Issues and Innovative Solutions; Alongi, J., Horrocks, A.R., Carosio, F., Malucelli, G., Eds.; Smithers Rapra: Shawbury, UK, 2013; pp. 207-238.

4. European Chemicals Bureau. European Union Risk Assessment Report for Bis(Pentabromodiphenyl) Ether; European Chemicals Bureau, Office for Official Publications of the European Communities, Luxembourg: 2003. Available online: https://echa.europa.eu/documents/10162/6434698/orats_final_rar_ bispentabromophenylether_en.pdf (accessed on 10 July 2020).

5. United States Environmental Protection Agency. An Alternatives Assessment for the Flame Retardant Decabromodiphenyl Ether (DecaBDE), Final Report. January 2014. Available online: https://www.epa.gov/ sites/production/files/2014-05/documents/decabde_final.pdf (accessed on 10 July 2020).

6. 3/227 of 9 February 2017 Amending Annex XVII to Regulation (EC) No 1907/2006 of the European Parliament and of the Council Concerning the Registration, Evaluation, Authorisation and Restriction of Chemicals (REACH) as Regards Bis(Pentabromophenyl)Ether. The European Parliament and of the Council, 2017.

7. Horrocks, A.R. Flame retardant/resistant coatings and laminates. In Advances in Flame Retardant Materials; Horrocks, A.R., Price, D., Eds.; Woodhead Publishing: Cambridge, UK, 2008; pp. 159-187. 
8. de Wit, C.A.; Herzke, D.; Vorkamp, K. Brominated flame retardants in the Arctic environment-Trends and new candidates. Sci. Total Environ. 2010, 408, 2018-2885. [CrossRef] [PubMed]

9. National Academy of Sciences. Toxicological Risks of Selected Flame-Retardant Chemicals; Sub-Committee on Flame-Retardant Chemicals of the United States National Research Council: Washington, DC, USA; National Academy Press: Washington, DC, USA, 2000.

10. Chaplin, D.; Brown, S.C. Flamtard-A new range of flame and smoke retardants. In Flame Retardants '90; Interscience Communications: London, UK, 1990; pp. 114-125.

11. Cusack, P.A.; Hornsby, P. Zinc Stannate-coated Filler: Novel flame retardant materials and smoke suppressants for polymeric materials. J. Vinyl Addit. Technol. 1999, 5, 21-30. [CrossRef]

12. Horrocks, A.R.; Smart, G.; Price, D.; Kandola, B. Zinc stannates as alternative synergists in selected flame retardant systems. J. Fire Sci. 2009, 27, 495-521. [CrossRef]

13. Horrocks, A.R.; Smart, G.; Kandola, B.K.; Holdsworth, A.F.; Price, D. Zinc stannate interactions with flame retardants in polyamides; Part 1: Synergies with organobromine-containing flame retardants in polyamides 6 (PA6) and 6.6 (PA6.6). Polym. Degrad. Stab. 2012, 97, 2503-2510. [CrossRef]

14. Horrocks, A.R.; Smart, G.; Kandola, B.; Price, D. Zinc stannate interactions with flame retardants in polyamides; Part 2: Potential synergies with non-halogen-containing flame retardants in polyamide 6 (PA6). Polym. Degrad. Stab. 2012, 94, 645-652. [CrossRef]

15. Holdsworth, A.F.; Horrocks, A.R.; Kandola, B.K.; Price, D. The potential of metal oxalates as novel flame retardants and synergists for engineering polymers. Polym. Degrad. Stab. 2014, 110, 290-297. [CrossRef]

16. Holdsworth, A.F.; Horrocks, A.R.; Kandola, B.K. Synthesis and thermal analytical screening of metal complexes as potential novel fire retardants in polyamide 6.6. Polym. Degrad. Stab. 2017, 144, 420-433. [CrossRef]

17. Holdsworth, A.F.; Horrocks, A.R.; Kandola, B.K. Novel metal complexes as potential synergists with phosphorus based flame retardants in polyamide 6.6. Polym. Degrad. Stab. 2020, 179, 109220. [CrossRef]

18. Weil, E.D.; Levchik, S. Flame Retardants for Plastics and Textiles; Hanser: Munich, Germany, 2009; pp. 88-91.

19. Holdsworth, A.F. Novel Multifunctional Fire and Smoke Retardants for Engineering Polymers. Ph.D. Thesis, University of Bolton, Bolton, UK, 2014.

20. Schaffer, M.A.; Marchildon, E.K.; McAuley, K.B.; Cunningham, M.F. Thermal non-oxidative degradation of nylon 6,6. JMS Rev.-Macromol. Chem. Phys. 2000, C40, 233-272. [CrossRef]

21. Lewin, M.; Weil, E.D. Mechanisms and modes of action in flame retardancy of polymers. In Fire Retardant Materials; Horrocks, A.R., Price, D., Eds.; Woodhead Publishing: Cambridge, UK, 2001; pp. 31-68.

22. Stec, A.A. Fire toxicity-The elephant in the room? Fire Saf. J. 2017, 19, 79-90. [CrossRef]

23. El-Mazry, C.; Ben Hassine, M.; Correc, O.; Colin, X. Thermal oxidation kinetics of additive free polyamide 6-6. Polym. Degrad. Stab. 2013, 98, 22-36. [CrossRef]

24. Horrocks, A.R.; Sitpalan, A.; Kandola, B.K. Design and characterisation of bicomponent polyamide 6 fibres with specific locations of each flame retardant component for enhanced flame retardancy. Polym. Test. 2019, 79, 106041. [CrossRef]

25. Satchell, D.P.N.; Satchell, R.S. Quantitative aspects of the Lewis acidity of covalent metal halides and their organo derivatives. Chem. Rev. 1969, 69, 251-278. [CrossRef]

26. Ismaeili, N. Mechanistic Study of Synergism of Inorganic Synergists with Flame Retardants. Ph.D. Thesis, University of Bolton, Bolton, UK, 2019.

27. Kicko-Walczak, E. Flame retarded halogenated unsaturated polyester resins. Thermal decomposition study. J. Polym. Eng. 2003, 23, 149-161. [CrossRef]

(C) 2020 by the authors. Licensee MDPI, Basel, Switzerland. This article is an open access article distributed under the terms and conditions of the Creative Commons Attribution (CC BY) license (http://creativecommons.org/licenses/by/4.0/). 